\title{
The late preterm IUGR and/or SGA
}

\author{
Enrico Bertino*, Luciana Occhi, Paola Di Nicola \\ From XX National Congress of the Italian Society of Neonatology \\ Rome, Italy. 9-11 October 2014
}

It is well known that in late preterm infants the mortality and the morbidity are higher than in term neonates. The rate of complications decreases with the progression of gestational age through the late preterm period [1]. Intrauterine growth restriction (IUGR) is one of the cause for late preterm delivery and it occurs more often in late preterm infants than terms ones. Itself constitutes a risk factor for morbidity and mortality $[2,3]$. IUGR, as well as associated peri-natal morbidities, contributes to increase the risk, in these infants, of postnatal growth impairment, metabolic diseases and poor neuro-developmental outcome [1,4]. Late preterm small for gestational age (SGA) infants were 44 times more likely to die in the first month and 22 times more likely to die in their first year than term adequate for gestational age (AGA) newborns. This increased risk cannot be fully explained by an increasing prevalence of lethal congenital conditions among SGA late preterm newborns [5].

The ability to recognize abnormal growth at birth and or a intrauterine malnutrition is of great importance for the care and the prognosis of these neonates. Neonatal anthropometric charts are commonly used for the diagnosis at birth of SGA newborns [6]. The terms SGA and IUGR are often used as synonyms, however they reflect two different concepts. SGA refers to a statistical definition, based on an auxological cross-sectional evaluation (prenatal or neonatal), and denotes a fetus or a neonate whose anthropometric variables (usually weight) are lower than a given threshold value computed on a set of infants having the same gestational age. IUGR instead refers to a clinical and functional condition and denotes fetuses unable to achieve their own growth potential. Such a condition can be assessed by ultrasonography during pregnancy by a longitudinal evaluation of fetal growth rate. The current gold standard in neonatal auxological evaluation is based on informations obtained from both neonatal anthropometric charts and intrauterine growth charts [7].

At present specific growth charts to monitor postnatal growth of late preterm infants are not available. In the next future the late preterm postnatal longitudinal growth standards will be available as a result of "Intergrowth 21st Project".

Published: 9 October 2014

\section{References}

1. Kugelman A, Colin AA: Late preterm infants: near term but still in a critical developmental time period. Pediatrics 2013, 132:741-751.

2. Dimitriou G, Fouzas S, Georgakis V, Vervenioti A, Papadopoulos VG, Decavalas G, Mantagos S: Determinants of morbidity in late preterm infants. Early Hum Dev 2010, 86(9):587-91.

3. Ortigosa Rocha C, Bittar RE, Zugaib M: Neonatal outcomes of late-preterm birth associated or not with intrauterine growth restriction. Obstet Gynecol Int 2010.

4. Goyal NK, Fiks AG, Lorch SA: Persistence of underweight status among late preterm infants. Arch Pediatr Adolesc Med 2012, 166(5):424-30.

5. Pulver LS, Guest-Warnick G, Stoddard GJ, Byington CL, Young PC: Weight for gestational age affects the mortality of late preterm infants. Pediatrics 2009, 123(6):e1072-1077.

6. Bertino E, Spada E, Occhi L, Coscia A, Giuliani F, Gagliardi L, Gilli G, Bona G, Fabris C, De Curtis M, Milani S: Neonatal anthropometric charts: the Italian neonatal study compared with other European studies. J Pediatr Gastroenterol Nutr 2010, 51(3):353-61.

7. Bertino E, Milani S, Fabris C, De Curtis M: Neonatal anthropometric charts: what they are, what they are not. Arch Dis Child Fetal Neonatal Ed 2007, 92:7-10.

doi:10.1186/1824-7288-40-S2-A3

Cite this article as: Bertino et al:: The late preterm IUGR and/or SGA. Italian Journal of Pediatrics 2014 40(Suppl 2):A3.

* Correspondence: enrico.bertino@unito.it

Neonatal Unit, University of Turin, 10126 Turin, Italy 